\title{
Arabic Alphabetic Puzzle Game Using Eye Tracking and Chatbot for Dyslexia
}

\author{
https://doi.org/10.3991/ijim.v12i5.8957
}

Nahla Aljojo( $\left.{ }^{\varpi}\right)$, Asmaa Munshi, Wfaa Almukadi

University of Jeddah, Jeddah, Saudi Arabia

naljojo@uj.edu.sa

Anhar Hossain, Noran Omar, Bashair Aqel, Shahad Almhuemli, Fatma Asirri, Areej Alshamasi

King Abdulaziz University, Jeddah, Saudi Arabia

\begin{abstract}
Dyslexia is a problem that an individual has since birth; it poses difficulties for the rest of their life, similar to other learning disabilities. Spelling, writing, reading and in certain instances speech can all be undermined by the language processing disorder. Idleness or a lack of intellect are not associated with dyslexia. Furthermore, sight problems do not cause dyslexia. Rather, data is evaluated and understood by the brain in alternative ways, making dyslexia a neurological ailment afflicting both children and grown-ups.

This paper seeks to devise a puzzle game application based on eye tracking, which will assist with focusing attention, as well as a chatbot that can motivate users. This should prove beneficial to individuals with dyslexia, parents of dyslexics, or experts such as reading professionals, instructors and teachers who are assisting dyslexics. Based on the best current understanding of how to assist dyslexics, we meticulously assessed every application prior to its inclusion.
\end{abstract}

Keywords—Dyslexia, Learning Disabilities, puzzle game, Arabic Alphabetic, Eye Tracking, Chatbot

\section{Introduction}

Learning Disabilities are representative of various conditions that may have a significant effect on learning and comprehension of verbal and non-verbal information. These types of disorders have a considerable impact on individuals' learning capabilities, among people who otherwise would possess average abilities that are crucial to thinking and reasoning. As a consequence of these kinds of disabilities, these individuals are generally unable to read and comprehend things in a manner that individuals of average ability would (Geary, 2016).

Furthermore, curiosity, entertainment and the type of challenges that are faced by dyslexics have a considerable effect on their learning, reading and educational potential. Children can enhance their reading capabilities through interacting with score 
counters on video games, alongside improving their basic reading skills via evaluation of the dialogue that is printed on-screen (Griffith University, 2002).

On the other hand, a cutting-edge technological application that has been recently developed that may contribute to the learning process is natural user interaction, for example the Microsoft Kinect device. This is based on natural user interaction, which can detect the movement and gestures of users and transfer them to the computer (Altanis et al., 2013).

Visual-based interventions, such as those in video modelling, have been identified as effective in providing learning opportunities to students suffering from spectrum disorders. This approach is considered highly useful and appropriate for individuals across various age groups and abilities. Contemporarily, increasing numbers of children have been diagnosed with learning disabilities, which has further enhanced the significance of using videos with the objective of strengthening individuals reading proficiency (Ganz et al., 2011).

The study's objective is to develop an application that may be directed towards children aged between 4 and 7 with dyslexia, which includes excessive movement and lack of attention. Individuals with an inability to read properly as a result of their disability (dyslexia) may utilise these kinds of applications to facilitate their learning process. This is basically a puzzle game comprising of eye tracking, which will ensure that the person is paying attention on the task and chatbot, which will assist the user with gaining motivation if the systems finds that the user is losing attention.

\section{Dyslexia}

Dyslexia is a neurological learning disability, characterised by difficulties with word acknowledgment, poor spelling and limited decoding abilities. Dyslexia should not be deemed an indication of poor knowledge or sluggishness. Additionally, dyslexia is not the consequence of weakened vision. Dyslexic youngsters and grown-ups essentially suffer from a neurological difficulty, causing their brains to process and translate data in an unanticipated manner. Trained experts can recognise dyslexia through utilising a formal assessment. The assessment considers an individual's capacity to comprehend and utilise spoken and written dialect. It considers areas of skill strengths and weaknesses that are required for reading. Furthermore, numerous different components can be considered, for example family history, cognitive processes, instructive foundation and social conditions (Dyslexia Toolkit, 2012).

\subsection{How Is Dyslexia Treated?}

Identifying dyslexia at an early stage in life is prudent. Adults with unidentified dyslexia regularly work in occupations that could be considered beneath their usual academic limit. However, with assistance from a mentor, instructor, or other trained and proficient individual, all dyslexics may become great readers and writers. Therefore, utilising the following techniques will enable dyslexia to be tackled more effectively (Dyslexia Toolkit, 2012): 
1. Looking for changes in the classroom. This may enable additional opportunities to be incorporated to complete assignments, assist with note taking, oral assessments, alongside various appraisal methods.

2. Exposing your child to early oral reading, writing, composing and drawing experience can be advantageous to them. Furthermore, practice with print information, essential letter arrangement, acknowledgment aptitude and semantic mindfulness can be beneficial, strengthening the connection between sound and significance.

3. Seeking assistance with the intense subject matter that emerges from the struggle to beat academic challenges.

4. Encouraging your child to read various types of writing. This incorporates books, magazines, promotions and funny stories.

5. Using audiobooks and assistive innovation. Illustrative examples are screen readers and voice acknowledgment PC software.

\subsection{Supporting Children with Dyslexia Strategies for Learning and Reading}

This section has explored how to assist children with learning and reading, which may be summarised below (Supporting Children with Dyslexia, 2017):

1. Sound and letters;

2. Meaning;

3. Sight Words;

4. Grammar.

- Sounds and Letters: Children must be able to understand the sounds that letters make, as opposed to simply their names. Children are taught sounds, while they also mix them together to make words, for example $\mathrm{p}-\mathrm{o}-\mathrm{t}=$ pot. Children must not end up focusing on the activity of 'sounding out', rather they should be urged to utilise and adjust techniques.

- Meaning: Children can regularly determine what a word means based on the identified importance of the sentence. At times, youngsters must be reminded to check that what they are perusing makes sense.

- Sight Words: The reason that location words are shown is that it permits children to strengthen their reading familiarity. If a child must make a concerted effort to read each single word, reading can become disheartening and tedious. With the chance that a child possesses a bank of words that they understand by location, reading familiarity may be enhanced and it can be simpler to interpret obscure words.

- Grammar: Children can utilise their insight into spoken dialect while reading. A few youngsters must be reminded to be mindful that what they are reading is accurate, for example 'They were playing' rather than 'They was playing'. 


\section{Impact of Android and chatbot applications on the reading abilities of disabled individuals}

Computer software that seeks to provide thought provoking discussion for a user is usually called a chatbot, which is a form of dialogue system. Numerous forms of dialogue system have been created. However, Satu and Parvez (2015) explained that due to simple installation and lightweight nature, the most commonly utilised chatbots are the Artificial Intelligence Markup Language (AIML) software.

While a learner is using the software, they must be provided with brief and significant responses, meaning that a question answering program may be effectively incorporated with a chatbot's conversational feature. Chatbots have primarily emerged from the computer science field and have been utilised by firms to provide a competitive advantage over the internet, although within a teaching context, learners' participation and holding of information has been effectively increased through chatbots. Furthermore, strengthened problem solving, comprehension, improved memory, response to a requirement for individual bonds during learning, simplified interaction and information procedures, motivation of crucial learning behaviours, an enhanced feeling of security and simplicity within the learning context, as well as greater enthusiasm, are all benefits of using chatbots and other educational systems. Goda et al. (2014) proposed that learners' interaction may be facilitated, if they communicated with a chatbot in English beforehand. The chatbot process is outlined in figure 1.

Chatbots store information within a knowledge web, where the relevant response is retrieved and provided to the system user. AIML, being a ruled-base language, means that Melsyanne's development proceeded through a collection of rules known as a data- driven programming paradigm. The rules comprise of two major sections, namely condition and action. Melsyanne works by selecting one rule that has its specific conditions satisfied. Subsequently, the action of the selected rule is executed. The category element defines the AIML rules. This element also comprises of the pattern and template element, which defines the conditions and actions (Odhiambo et.al, 2017).

A significant effect on the degree of personal learning is seen not just from chatbots, because various forms of Android application exist. The online interface is used to input words, which can then be engaged with by the learner through the apparatus interface. Through pressing the apparatus' screen, a particular word can be selected from the vocabulary set that is arranged in an ordered manner. The word is then read out by the program. In this manner, a word can be related to a particular picture by the student through having each interface. A further example of this is the iOS device interface, where a learner can take a picture of an object in their surroundings after they have chosen a term or word from their vocabulary. As Campigotto et al. (2013) explained, in relation to a particular word in the system, a learner can search their computer's stored picture files to select a related image, taking advantage of the internet interface. 


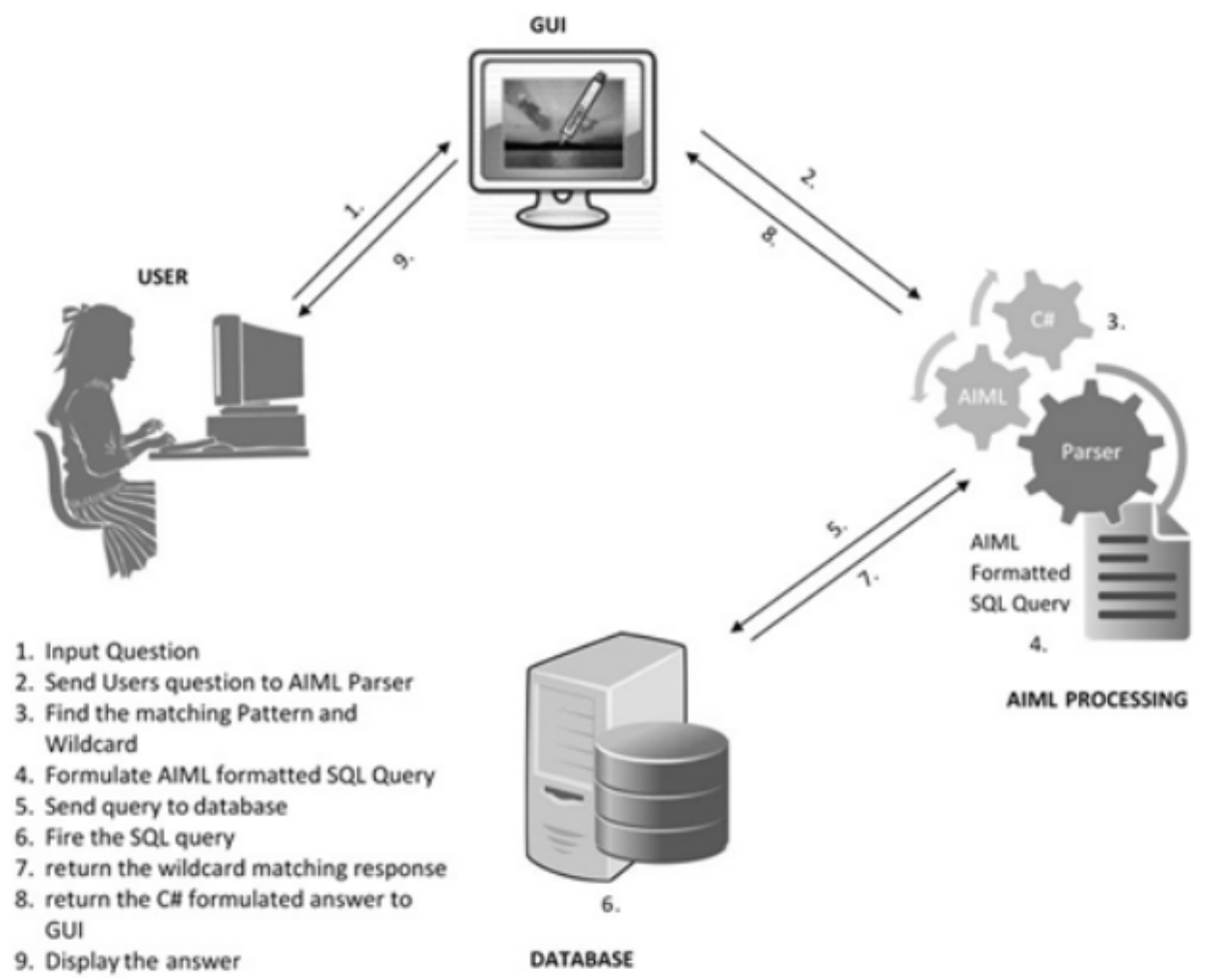

Fig. 1. Chatbot Architecture (Source: Abbasi \& Kazi, 2014)

\section{$4 \quad$ Literature Review}

This section investigates the previous applications relating to learning disability and dyslexia, thus providing a clear comprehension of the technology utilised in previous works. Many relevant studies are apparent in the existing literature, several of which are discussed in this section.

\subsection{Sight Words Superhero}

There is a 13 times greater occurrence in the commonest 1000 words over the subsequent 1000 commonest words. Therefore, in terms of literacy skills, more positive effects will be seen through becoming adept with this comparatively limited word set. As Shah (1012) explained, the application is compatible with the iPod touch, iPad and iPhone, with suitability for children aged four and over. A number of prominent characteristics can be noted. Firstly, incremental learning stages are encouraged; collections of 20 words, separated into 50 groups, are identified from the 1000 words, meaning that the 1000 words will not engulf young children. Secondly, an organised approach can be taken, with vocabulary that has been successfully tackled being high- 
lighted, thus permitting an emphasis on specific problem vocabulary. Thirdly, progress can be recorded, with the amount of words learnt being indicated in relation to every group. Fourthly, motivation is provided, as a tick mark is presented next to a group once its full vocabulary has been mastered. Fifthly, quizzes for the learner can be provided by their parents, with an overview of the vocabulary they have learnt rapidly accessible on a dedicated review page, presenting the tick marks for completed groups and the vocabulary they groups comprise of. Lastly, as many as three user accounts can be set on the app, with monitoring and tick marks provided for each of the accounts.

\subsection{Pics 1 Word - Free}

With the learner engaging in a process of using images to identify the correct work, this app provides an entertaining puzzle game. It is compatible with iPod, iPad and iPhone. As Lotum Gmbh (2017) has explained, there are a number of characteristics of this app. Firstly, different levels of the game are unlocked by a user identifying the right words. The makers of the game regularly update the app with more puzzles, with a spread of puzzles from simple to difficult being provided. Secondly, a user can instantly begin tackling the puzzles, with simple rules and creating a user account unnecessary. Thirdly, the aim of the game is to assess four images, identify their shared characteristic and thus guess the word. Fourthly, the game is available in 8 different languages, with more than $222,000,000$ players internationally.

\subsection{A+ Spelling Test}

A tailored vocabulary set can be formulated for learners through this free spelling app. It encourages self-guided learning among children, who can revise and undertake the quizzes as they wish, through the simple adaptable characteristics and interface. There is a simple test procedure, whereby email or screen grabs can be used by the learners to send their test scores. Children aged between 6 and 8 are focused on by this app. Three different tests are utilised, which are 'ace it', 'unscramble' and 'practice', which provides the amount of letters in the word. As Innovative Mobile Apps (2017) explained, the app is compatible with the iPad and iPhone. The stages outlined here explain how the app is used. Stage one is accessing the main page, where every word set of the user is presented. A further set of vocabulary can be added for a spelling test through pressing the plus button. Stage two is accessing the formulated word set. The word set can be added to by pressing the plus button. After entering the new word, by pressing the red record icon the app will record the use speaking the word. Additional words can be inputted through pressing 'next'. Stage three is when the three kinds of tests can be undertaken by the students, namely ace it, unscramble or practice, once the vocabulary sets have been created. Stage four involves the learner undertaking a marked test after they are fully prepared; the student will spell a word after the app plays the recording of the word being spoken. The speaker button can be pressed if the learner wishes to hear the word another time. If the learner spells the word wrongly, the right spelling will be provided. Stage five concerns the altera- 
tion of the apps settings, for example whether during the spelling assessment, immediate feedback is provided to the student. Furthermore, the assessment can be undertaken by further learners on the same apparatus, as assessment grades can be deleted. This is all possible through the cog symbol on the main page.

\subsection{A1 Spelling App}

Through enabling children to hear vocabulary being spoken and through engaging in repeated processes to aid recall, the A1 Spelling App helps with learning to spell. Child-appropriate images are included beside the words. There are 6 sets of vocabulary, with over 150 words in total. Simple words begin the set and they become progressively more challenging. Out of all of the sets, the largest is the 'other' collection, which includes words that children should be able to use due to their pervasive nature. An advantage of the app is that parents need to provide little assistance, because small children will find it straightforward to use. Power Math Apps LLC (2010) noted the app's compatibility with the iPod touch, iPad and iPhone.

\subsection{ABC Magic Phonics - Learning Sounds and Letters}

An essential skill during reading is to know the alphabet's different sounds, which ABC Magic Phonics assists children with. Improved reading skills will be acquired by a child, through the technique of becoming familiar with phonemes. To assist young learners with knowing each letter's sound, a photo is provided for each phonetic. The app is compatible with the iPod Touch, iPad and iPhone, with suitability for children aged five and below. PreSchool University (2010) explained that there are various adaptable characteristics of the app, such as being able to set the letters that a learner will tackle first. Further characteristics of the app can be explained. Firstly, it is recommended that lowercase letters are provided to the child initially. Secondly, it is suggested that learners' reading abilities will be improved by knowing the letter sounds. Thirdly, children will be able to recall the letter sounds by engaging in repeated practice and understanding words' rhythms. Fourthly, the letter sounds will be learnt more effectively through coloured letters and the use of photos. Fifthly, each word and sound is spoken by the learners. Lastly, in order to facilitate a child's acquisition of the fundamental capability of knowing the sounds of a letter and tying them to images, the app is streamlined and simple to maintain the child's concentration.

\subsection{Leo-Recorder and Transcriptions}

Leo provides the simplest method for recording your thoughts and transcribing your voice. It is designed particularly for people with dyslexia or a learning disability, aged 4 years and above. It is intended to assist a user with getting their thoughts on paper via real time transcription. Zelig, LLC (2017) exclaimed that "This app is simply incredible at transcribing voice to text! "Writing" has never been so fast and this 
much fun". The app is designed for use on both iPhone and iPad. It has numerous features that can be outlined as follows:

1. Thoughtful Design - Each aspect of the experience has been designed around people with learning disabilities, for example the font selection, simple user interface and the ability to edit.

2. Backed Up and Secure Forever: All recordings are backed up using the iCloud Drive, which is encrypted by Apple. Only the user can access their recordings.

3. Organised: All the user's recordings are searchable and categorised in a beautiful calendar.

4. Transcription: the recorder transcribes the user's voice in real time, enabling them to search through all of their recordings.

5. Editable: Transcriptions may be edited at any time, while - notifications can be provided daily to record a note.

6. Prompts: The app comes with built-in prompts that alter according to the time of day. It is also customisable, with the possibility of adding one's own prompts and choosing from 6 different themes.

\subsection{Reading Machine Free}

An innovative approach to entry-level reading has been taken by the app Reading Machine, which has been supported on Apple devices. Through presenting how a word's sounds and letters are combined, the reading procedure is facilitated and the app's objective of diminishing annoyance among learners is achieved. As Diana Sharp Consulting (2010) explained, the process is that a learner is able to enter a word into the Reading Machine, if they cannot read it or it is a new word. The learner is able to attempt to understand the word by merging the different phonemes that are played by the app, which draws on a dictionary of more than 5000 words. The app will read the word out if the learner requires further assistance.

Because the learner is not just guessing or learning the words by rote, instead being compelled to break down the word to gain understanding, improved reading skills will be acquired by the child. So that reading capabilities of a high-standard can be cognitively formed, this manner of sound and letter understanding is crucial, according to the app's developers. Furthermore, with self-guided learning of unfamiliar words being engaged in, empowerment of the user occurs through the app. The learner will not be self-conscious about any lack of knowledge they have, rather reading will become engaging for a child whether they are dyslexic or an entry-level reader. A more sophisticated reading ability will be facilitated among children, while reading will be exciting, if this app is utilised. It is compatible with the iPod Touch, iPad and iPhone, while being suitable for children aged 4 and over.

\section{$5 \quad$ Methodology}

The research's overall methodology comprised of four stages: 
Stage 1: Review of the existing literature and previous works relating to applications for dyslexia

Stage 2: Interview - An interview was undertaken with a Psychological Counsellor from the Brain Training and Psychological Counselling Office, who possessed general expertise in the field of children's education, as well as specific knowledge of special needs (learning difficulties). The interview focused on methods for teaching children the fundamentals of the Arabic language. Furthermore, a discussion with the Psychological Counsellor was had in relation to how to teach this category of children the basic Arabic letters and words in a simple and effective manner, while also being engaging and entertaining. It was decided to focus on building the capabilities of children aged between 4 and 7 .

There numerous issues that we were unaware of, for example what the right educational approach is for children in this category. However, the Psychological Counsellor explained all the answers to us, with the common characteristic that these children find it challenging to differentiate between the similar letters. Therefore, there education should be founded on this basis, with each group distinguished based on similar characters (for example $\lrcorner, j, j, J$ ). We must teach dyslexic children these letters first and how to pronounce words that contain them correctly, followed by all of the different sounds of the letter, as well as all cases of the letter (in the beginning, middle and end of the word). Moreover, a psychological counsellor explained to us the significance of undertaking exercises after each class, which will assist students with developing their thinking and activating their brains. It can also confirm the knowledge that they possess, with repetition of these exercises being particularly useful for dyslexics. The psychological counsellor then explained to us the appropriate educational methods, including the use of voices and images to attract attention and expand awareness. Further, this will increase the absorption of this category, with the use of words stimulating and encouraging learners, thus strengthening their confidence and enthusiasm.

Afterwards, the counsellor discussed how to control children who suffer from hyperactivity and poor attention by focusing their eye movement. This means that their focus is less likely to be dispersed. Learners should also take regular breaks from learning and rest for some time, Furthermore; the psychological counsellor showed us 2 applications for learning disabilities. The first one had a speaking feature that can assist dyslexics with learning the correct way to pronounce letters; the second application was a standard puzzle app, which combines fun with education.

Stage 3: Prior Questionnaire The data that we required to assess the children's learning game applications was collected through distributing a questionnaire via social media platforms, for example Twitter and WhatsApp. The parent sample size according to the replies received was 317 , while the sample size of or the professionals working with dyslexics (teachers, tutors, reading specialists and so forth) was 11 , based on the replies received.

Prior to constructing the educational application for dyslexic children, we distributed a questionnaire that explored some crucial aspects, for example: Have you ever used this kind of application that helps you to teach your children how to learn if they are dyslexic?; Do you support the idea of establishing an educational application that helps with your child's reading skills from an early age (4-7 years) and before they 
join school?; Do your children spend a long time using their smart devices?; Does the smart device increase children's awareness in a positive way? The complete survey is presented below in section 6 .

Stage 4: Design and implementation of the application - We have outlined how certain applications teach children how to pronounce letters correctly in English, while also teaching them some words. Furthermore, we have created an application for dyslexics in Arabic using eye tracking and a chatbot, where the child is helped with correct pronunciation of the Arabic letters within the formats. In the Arabic language, the three primary formats are fatha, dama and kasra; the application is able to pronounce these formats correctly for the child. See section 7

Stage 5: Usability testing - Usability testing is the process of working with endusers directly and indirectly to assess how the user perceives a software package and how they interact with it. This process will uncover areas of difficulty for users as well as areas of strength. The goal of usability testing should be to limit and remove difficulties for users and to leverage areas of strength for maximum usability (Testingbrain, 2016). Usability testing is a technique for ensuring that the intended users of a system can carry out the intended tasks efficiently, effectively and satisfactorily. It also enables app developers to understand audience needs and, in return, produce stronger and more effective sites (Testingbrain, 2016).

Talking about website usability, (Nielsen, 2003) describes usability as a "...quality attribute that assesses how easy user interfaces are to use" and provides the following five principles that could use to measure the usability see table 6.3. These criteria were used to all tasks in our application and to both of users and administrators (Nielsen, 2003). It is important to the testing to prepare three kinds of questionnaire:

a) Pre Test Questionnaire: As shown in Appendix A, this kind questionnaire is to ensure that participants meet the required characteristics and skills to do the test and to know the background of the users their preferred languages, gender and their behavior in using the internet and how they dealing with the application. In addition, to capture the users feedback about every task in the application and what are the difficulties they faced during each tasks and what are the recommendations about each task. The users have to fill this questionnaire after each task in the test. See section 8

b) Post Test Questionnaire: As shown in Appendix A, this kind questionnaire is to capture the user's feedback about whole application and what are the difficulties they faced after finishing the test then what are the recommendations about the application. The users have to fill this questionnaire after finishing the test. See section 8

\section{Results of Prior Questionnaire}

Ranking analysis was applied to the parents $(\mathrm{N}=317)$ and the professionals who work with dyslexics $(\mathrm{N}=11)$ results, in order to rate the quality of the Arabic Alphabetic Puzzle Game Using Eye Tracking and Chatbot for Learning Disability (Dyslex- 
ia) from their perspectives. The overall attitudes conveyed in response to each question are displayed in Tables 1 and 2

Table 1. the parents' responses to the questionnaire

\begin{tabular}{|c|c|c|c|c|c|c|c|}
\hline \multirow[t]{2}{*}{ Question } & $\begin{array}{c}\text { Strong- } \\
\text { ly } \\
\text { Agree } \\
\end{array}$ & Agree & $\begin{array}{c}\text { Somehow } \\
\text { Agree }\end{array}$ & $\begin{array}{c}\text { I don't } \\
\text { Agree }\end{array}$ & \multirow[t]{2}{*}{ Mean } & \multirow[t]{2}{*}{$\begin{array}{l}\text { Standard } \\
\text { Deviation }\end{array}$} & \multirow[t]{2}{*}{ Attitude } \\
\hline & $\%$ & $\%$ & $\%$ & $\%$ & & & \\
\hline $\begin{array}{l}\text { 1- This application that } \\
\text { relies on E-learning helps to } \\
\text { improve your child's educa- } \\
\text { tional performance. }\end{array}$ & 41.9 & 34 & 21 & 0 & 24.22 & 5.8 & $\begin{array}{c}\text { Strongly } \\
\text { Agree }\end{array}$ \\
\hline $\begin{array}{l}\text { 2- I support the idea of using } \\
\text { fun games to teach children } \\
\text { who have difficulty reading }\end{array}$ & 41.6 & 27.6 & 22.9 & 7.9 & 25 & 4.75 & $\begin{array}{c}\text { Strongly } \\
\text { Agree }\end{array}$ \\
\hline $\begin{array}{l}\text { 3- Smart devices help im- } \\
\text { prove the reading level of } \\
\text { children who have difficulty } \\
\text { reading effectively and who } \\
\text { lack a positive manner }\end{array}$ & 31.6 & 27.6 & 22.9 & 17.9 & 25 & 4.75 & $\begin{array}{c}\text { Strongly } \\
\text { Agree }\end{array}$ \\
\hline $\begin{array}{l}\text { 4- Most children who have } \\
\text { difficulty reading spend a lot } \\
\text { of time using smart devices. }\end{array}$ & 18.7 & 31.4 & 31.1 & 18.7 & 24.9 & 4.35 & Agree \\
\hline $\begin{array}{l}\text { 5- Integration between } \\
\text { education and play in E- } \\
\text { learning applications is } \\
\text { an important way of engag- } \\
\text { ing children who have } \\
\text { difficulty reading. }\end{array}$ & 51.7 & 35.9 & & & 21.9 & 3.89 & $\begin{array}{c}\text { Strongly } \\
\text { Agree }\end{array}$ \\
\hline $\begin{array}{l}\text { 6- I support the idea of } \\
\text { downloading any learning } \\
\text { application that helps to } \\
\text { improve my child's reading } \\
\text { level. }\end{array}$ & 54.9 & 30.5 & 12.7 & & 23.77 & 4.52 & $\begin{array}{c}\text { Strongly } \\
\text { Agree }\end{array}$ \\
\hline $\begin{array}{l}\text { 7- Learning to read through } \\
\text { relevant multi - media is the } \\
\text { most effective way of teach- } \\
\text { ing children who have } \\
\text { difficulty reading effectively } \\
\text { and maintaining a positive } \\
\text { approach. }\end{array}$ & 38.7 & 40 & 17.8 & & 19.71 & 2.58 & Agree \\
\hline $\begin{array}{l}\text { 8- Motivational phrases can } \\
\text { encourage a child to spend } \\
\text { more time learning. }\end{array}$ & 75.6 & 19.4 & & & 23.75 & 4.68 & $\begin{array}{c}\text { Strongly } \\
\text { Agree }\end{array}$ \\
\hline $\begin{array}{l}\text { 9- Repetition of character } \\
\text { pronunciation or words } \\
\text { helps children with learning } \\
\text { difficulties to read. }\end{array}$ & 70.5 & 24.1 & & & 23.65 & 4.77 & $\begin{array}{c}\text { Strongly } \\
\text { Agree }\end{array}$ \\
\hline
\end{tabular}


Table 2. Responses to the questionnaire from professionals who work with dyslexics

\begin{tabular}{|c|c|c|c|c|c|c|c|}
\hline \multirow[t]{2}{*}{ Question } & $\begin{array}{c}\text { Strongly } \\
\text { Agree }\end{array}$ & Agree & $\begin{array}{c}\begin{array}{c}\text { Somehow } \\
\text { Agree }\end{array} \\
\end{array}$ & $\begin{array}{c}\text { I don't } \\
\text { Agree }\end{array}$ & \multirow[t]{2}{*}{ Mean } & \multirow{2}{*}{$\begin{array}{l}\text { Standard } \\
\text { Deviation }\end{array}$} & \multirow[t]{2}{*}{ Attitude } \\
\hline & $\%$ & $\%$ & $\%$ & $\%$ & & & \\
\hline $\begin{array}{l}\text { 1- This application that } \\
\text { relies on E-learning helps } \\
\text { to improve your child's } \\
\text { educational performance. }\end{array}$ & 35.9 & 40 & 11 & 10 & 22.12 & 4.3 & Agree \\
\hline $\begin{array}{l}\text { 2- I support the idea } \\
\text { of using fun games to teach } \\
\text { children who have difficul- } \\
\text { ty reading }\end{array}$ & 45.9 & 23.3 & 16.3 & 14.4 & 22 & 2.75 & $\begin{array}{c}\text { Strongly } \\
\text { Agree }\end{array}$ \\
\hline $\begin{array}{l}\text { 3- Smart devices help to } \\
\text { improve the reading level } \\
\text { for children who have } \\
\text { difficulty reading effective- } \\
\text { ly and lack a positive } \\
\text { approach }\end{array}$ & 41.3 & 37.9 & 10.9 & 22.9 & 15 & 2.88 & $\begin{array}{c}\text { Strongly } \\
\text { Agree }\end{array}$ \\
\hline $\begin{array}{l}\text { 4- Most children who have } \\
\text { difficulty reading spend } \\
\text { a lot of time using smart } \\
\text { devices. }\end{array}$ & 13.2 & 36.9 & 21.3 & 28.8 & 14.9 & 2.01 & Agree \\
\hline $\begin{array}{l}\text { 5- Integration between } \\
\text { education and play in E - } \\
\text { learning applications is } \\
\text { an important method for } \\
\text { attracting children who } \\
\text { have difficulty reading. }\end{array}$ & 33.7 & 66.9 & & & 18.29 & 2.98 & Agree \\
\hline $\begin{array}{l}\text { 6- I support the idea of } \\
\text { downloading any learning } \\
\text { application that helps to } \\
\text { improve my child's reading } \\
\text { level. }\end{array}$ & 60.9 & 38.5 & 10.3 & & 27.77 & 14.22 & $\begin{array}{c}\text { Strongly } \\
\text { Agree }\end{array}$ \\
\hline \begin{tabular}{|l|} 
7- Learning to read using \\
associated multi - media is \\
the most effective way to \\
teach children who have \\
difficulty reading effective- \\
ly and lack a positive \\
approach. \\
\end{tabular} & 28.7 & 50 & 17.4 & & 21.1 & 3.9 & Agree \\
\hline $\begin{array}{l}\text { 8- Motivational phrases } \\
\text { encourage children to } \\
\text { spend more time learning. }\end{array}$ & 20.6 & 75.0 & & & 21.25 & 4.65 & Agree \\
\hline $\begin{array}{l}\text { 9- Repetition of character } \\
\text { pronunciation or words } \\
\text { assists children who find it } \\
\text { difficult to read. }\end{array}$ & 70.3 & 14.2 & & & 33.21 & 3.32 & $\begin{array}{c}\text { Strongly } \\
\text { Agree }\end{array}$ \\
\hline
\end{tabular}




\section{$7 \quad$ Design and Implementation of the Application}

The system used SQLite to create physical database. The system physical database involves the actual design of a database according to the requirements that were established during the system logical design. During physical design, objects such as tables and columns are created based on entities and attributes that were defined during app logical design, thus we have utilised the Android Studio programme and Java to design and develop the application. Furthermore, we adopted Photoshop to design the backgrounds, letters and the words. Additionally, we used Eye tracking is a sensor technology that enables a device to know exactly where your eyes are focused. It determines your presence, attention, focus, drowsiness, consciousness or other mental states. This information can be used to gain deep insights into consumer behavior or to design revolutionary new user interfaces across various devices (tobii, 2018), also a chatbot (sometimes referred to as a chatterbot) is a computer program that attempts to simulate the conversation or "chatter" of a human being via text or voice interactions. A user can ask a chatbot a question or make a command, and the chatbot responds or performs the requested action (Rouse, 2018). The application comprises of numerous tasks, which are illustrated in figure 2.

\section{SYSTEM DESIGN}
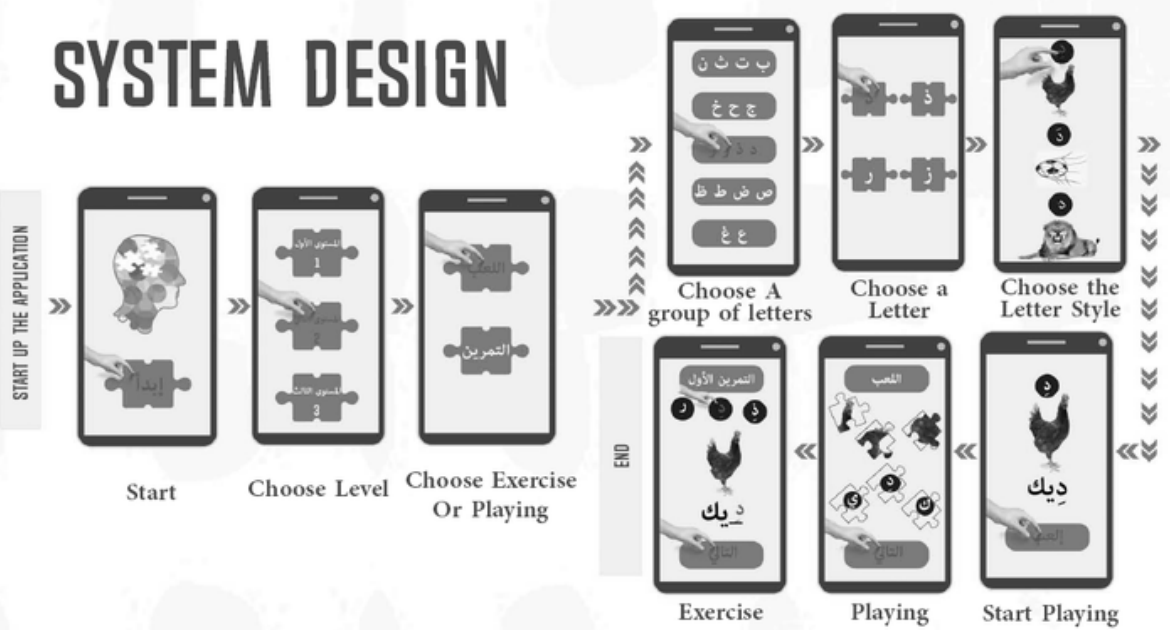

Fig. 2. System Design for the Arabic Alphabetic Puzzle Game for dyslexics, using eye tracking and a chatbot

Main screens: The first main screen includes a place for the logo and start button.

Level section: When the user begins the application, it will display the available levels and section screens in a simple manner

Exercise selection or playing: After the user chooses the level, a screen appears that asks the user to either continue with the exercise or undertake a tutorial.

Choose a group of similar letters: When the user chooses to play, this screen appears and displays all letter groups, asking the user to select the required one. 
Choose the letter: The user selects the group of similar letters; they will use one letter from this similar letter group.

Start Playing: The user will select the letter vowels and then will click to start playing.

Playing: We show the puzzle images and puzzle letters, asking the children to form a complete image.

\section{$8 \quad$ Results of Usability testing}

\subsection{Participants and Study Design}

20 children to test the children function in the application. The participants were aged four to seven years old. We are attending application usability testing conducted at brain training and collation Center and some children at home. Test date starts from Wednesday 14 March 2018 to Wednesday 21 March 2018.

\subsection{Criteria of Measuring Usability}

Talking about website usability, (Nielsen, 2003) describes usability as a "...quality attribute that assesses how easy user interfaces are to use" and provides the following five principles that could use to measure the usability see table 3 . These criteria were used to all tasks in our website and to both of users and administrators (Nielsen, 2003).

Table 3. Criteria of Measuring Usability According to (Nielsen, 2003)

\begin{tabular}{|l|l|l|l|l|l|}
\hline \multicolumn{1}{|c|}{ Measure } & $\begin{array}{c}\text { Strongly } \\
\text { Agree }\end{array}$ & Agree & Disagree & $\begin{array}{c}\text { Strongly } \\
\text { Disagree }\end{array}$ & $\begin{array}{c}\text { No } \\
\text { Opinion }\end{array}$ \\
\hline $\begin{array}{l}\text { Learnability: How easy is it for users to } \\
\text { accomplish basic tasks the first time they } \\
\text { encounter the design? }\end{array}$ & & & & & \\
\hline $\begin{array}{l}\text { Efficiency: Once users have learned the } \\
\text { design, how quickly can they perform tasks? }\end{array}$ & & & & & \\
\hline $\begin{array}{l}\text { Memorability: When users return to the } \\
\text { design after a period of not using it, how } \\
\text { easily can they reestablish proficiency? }\end{array}$ & & & & & \\
\hline $\begin{array}{l}\text { Errors: How many errors do users make, how } \\
\text { severe are these errors, and how easily can } \\
\text { they recover from the errors? }\end{array}$ & & & & & \\
\hline $\begin{array}{l}\text { Satisfaction: How pleasant is it to use the } \\
\text { design? }\end{array}$ & & & & & \\
\hline
\end{tabular}




\subsection{Analyze the results of pre-test questionnaire}

\section{For children}

Task 1: start the game

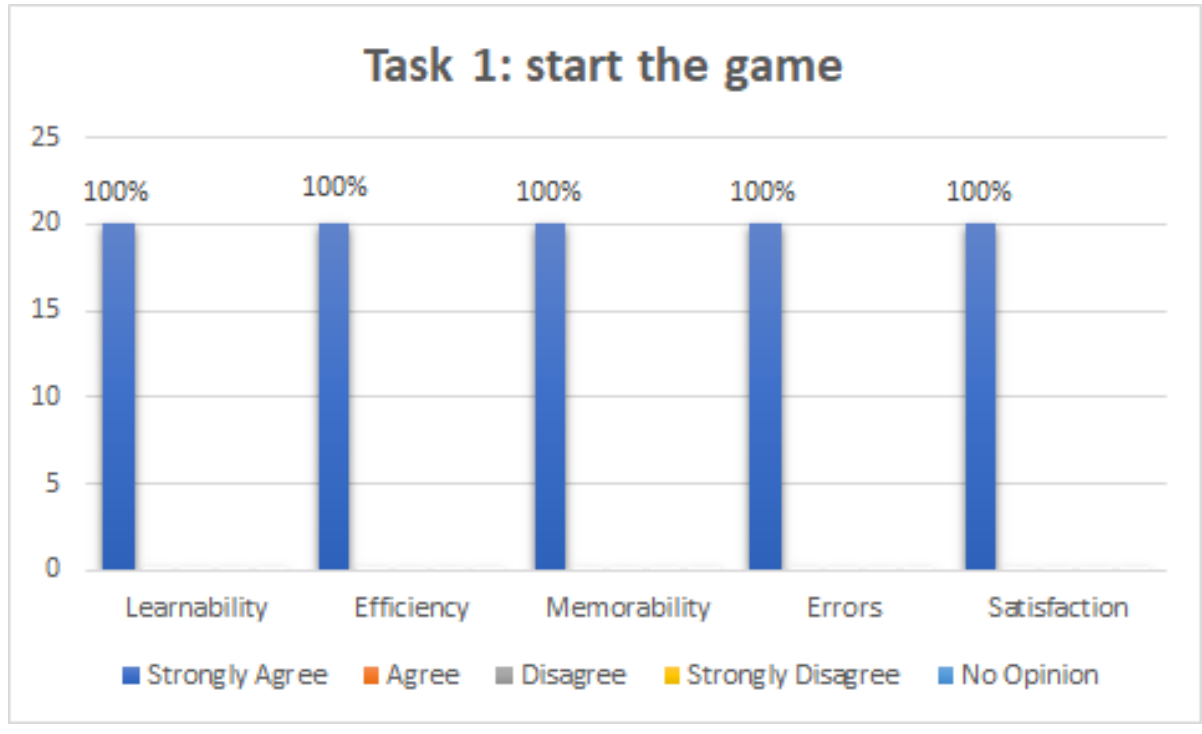

Fig. 3. pre-test "Task1" for children

Task 2: choose the game level

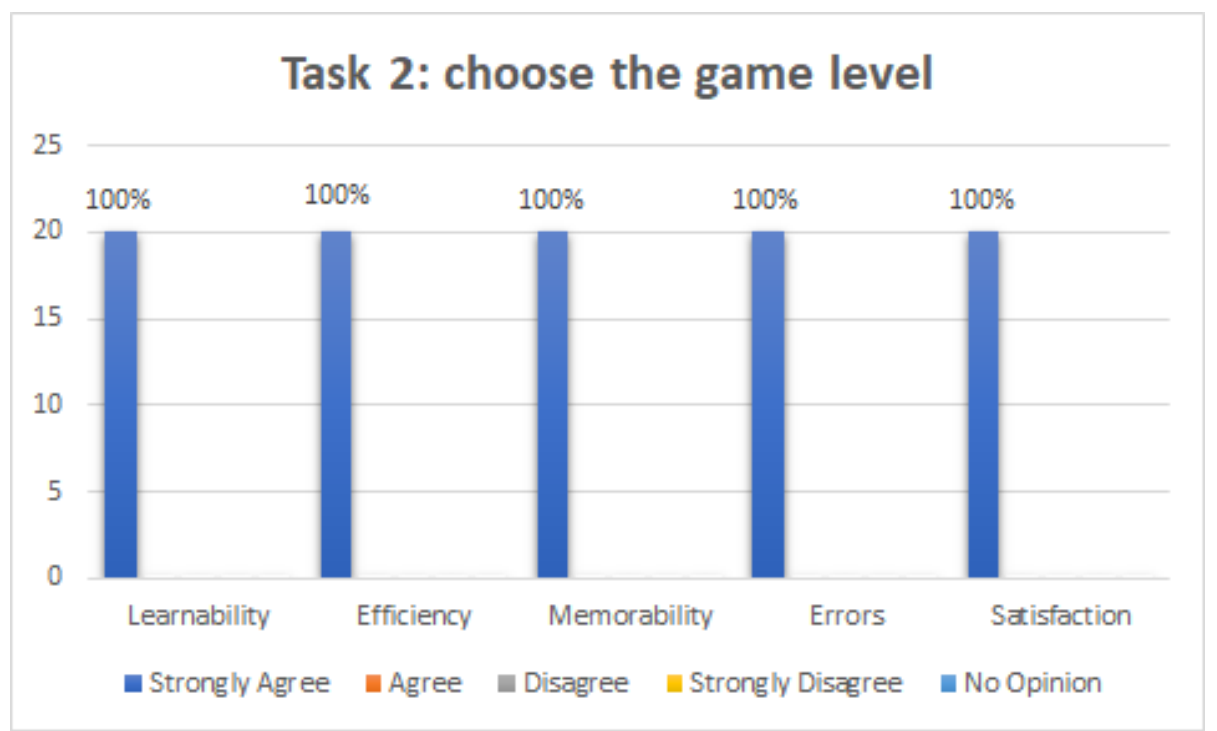

Fig. 4. pre-test "Task2" for children 
Task 3: play the game

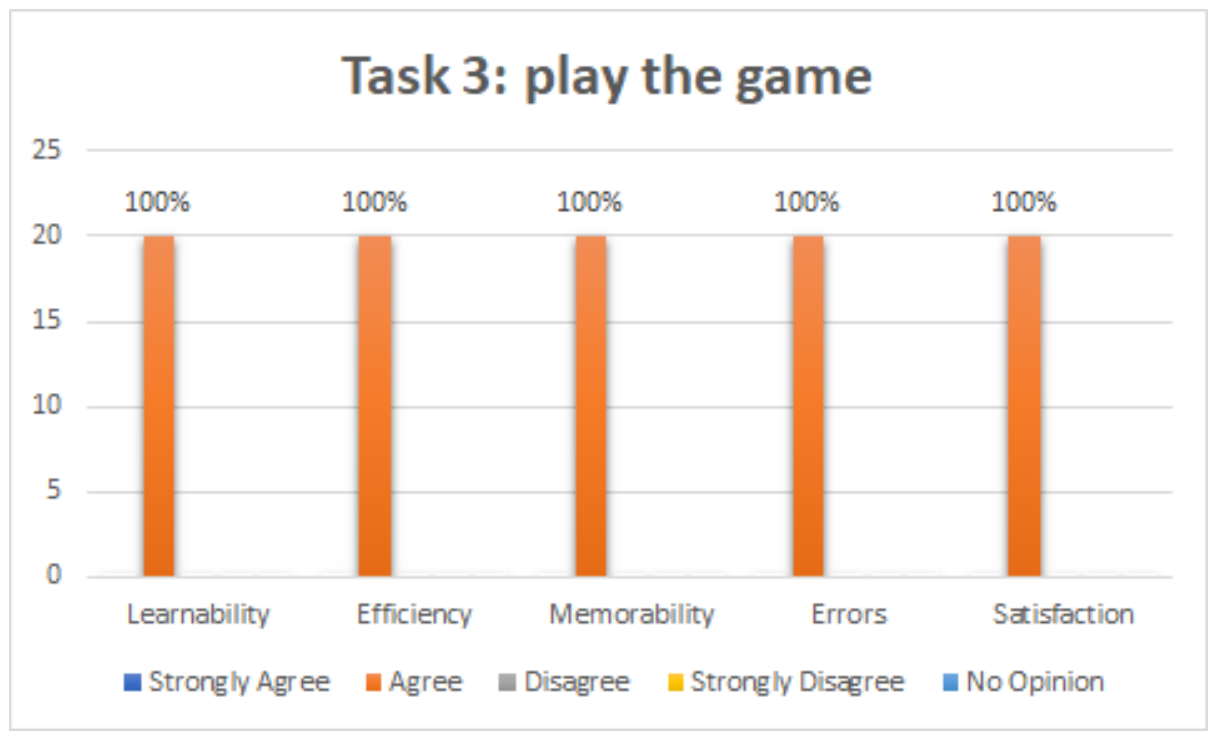

Fig. 5. pre-test "Task3" for children

Task 4: play exercise

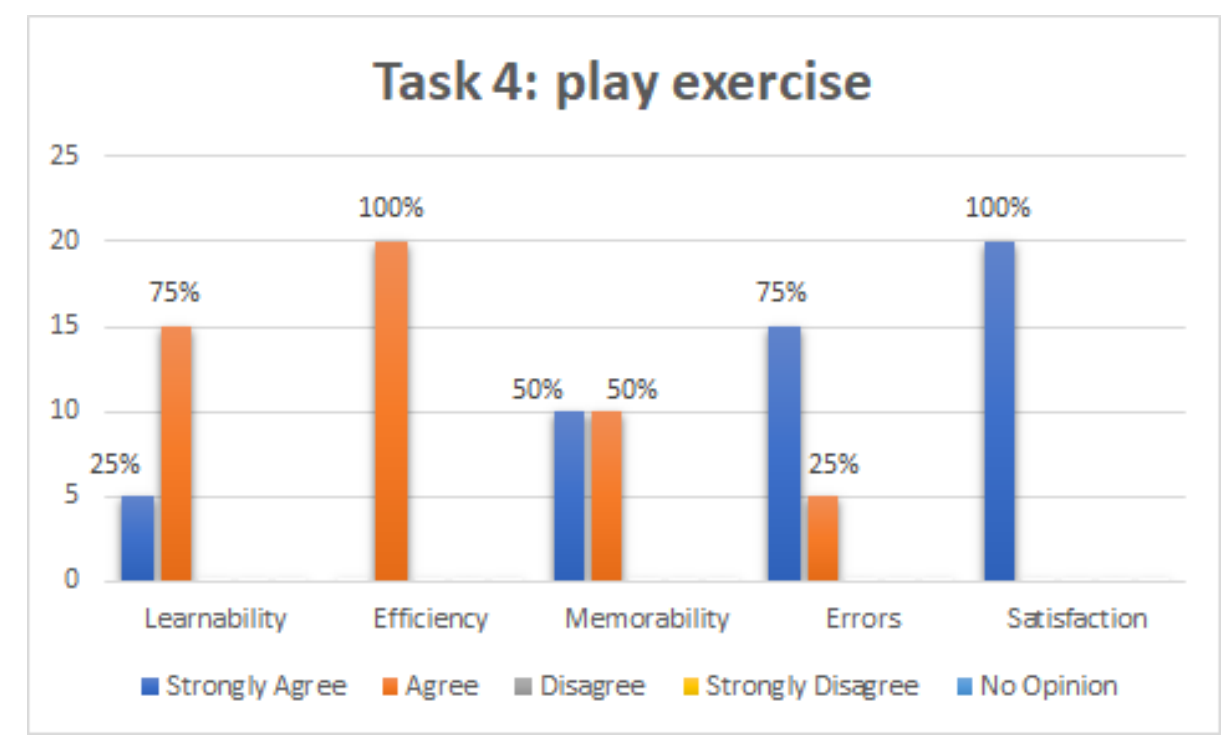

Fig. 6. pre-test "Task4" for children 
Task 5: choose group of similar letters

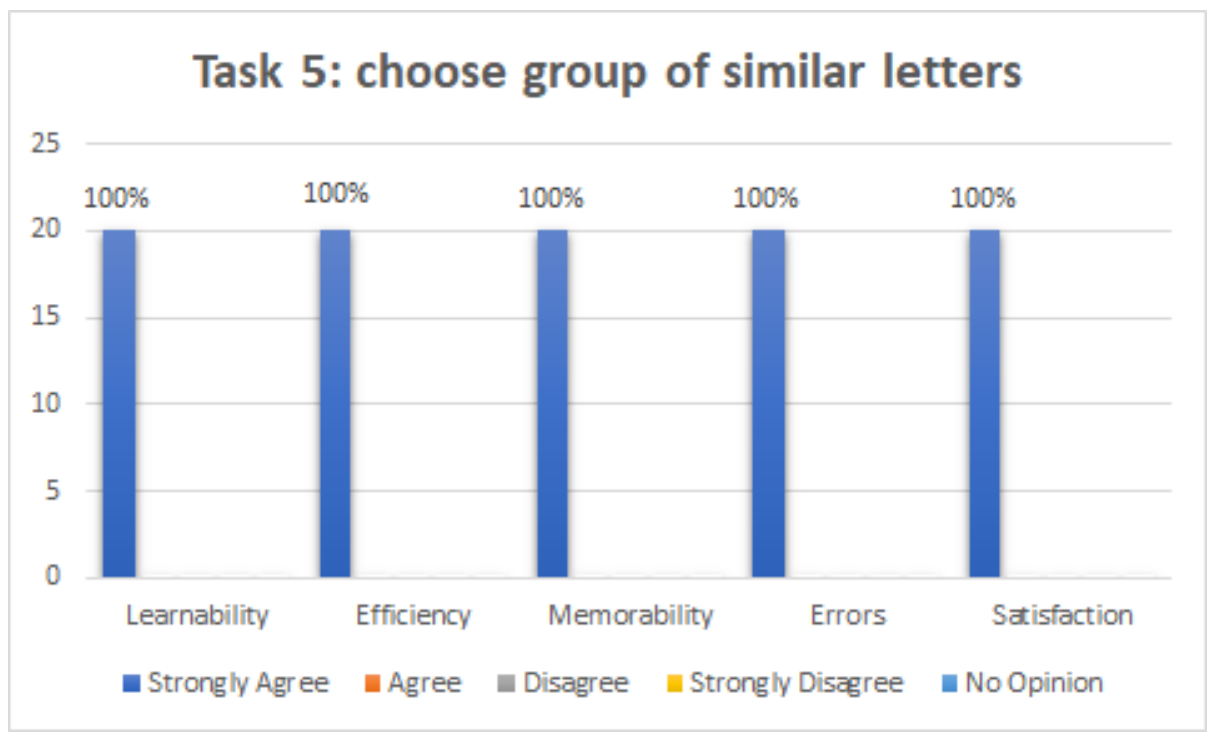

Fig. 7. pre-test "Task5" for children

Task 6: choose the vowel of the letter

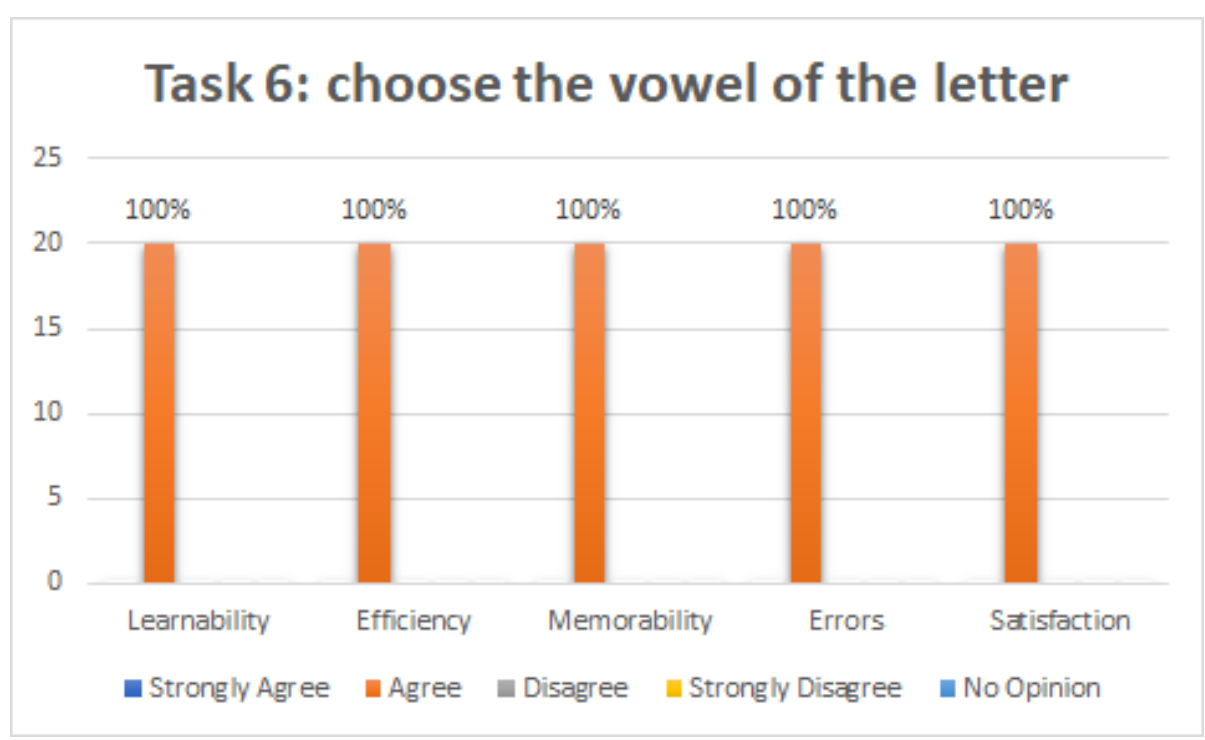

Fig. 8. pre-test "Task6" for children 
Task 7: choose letter

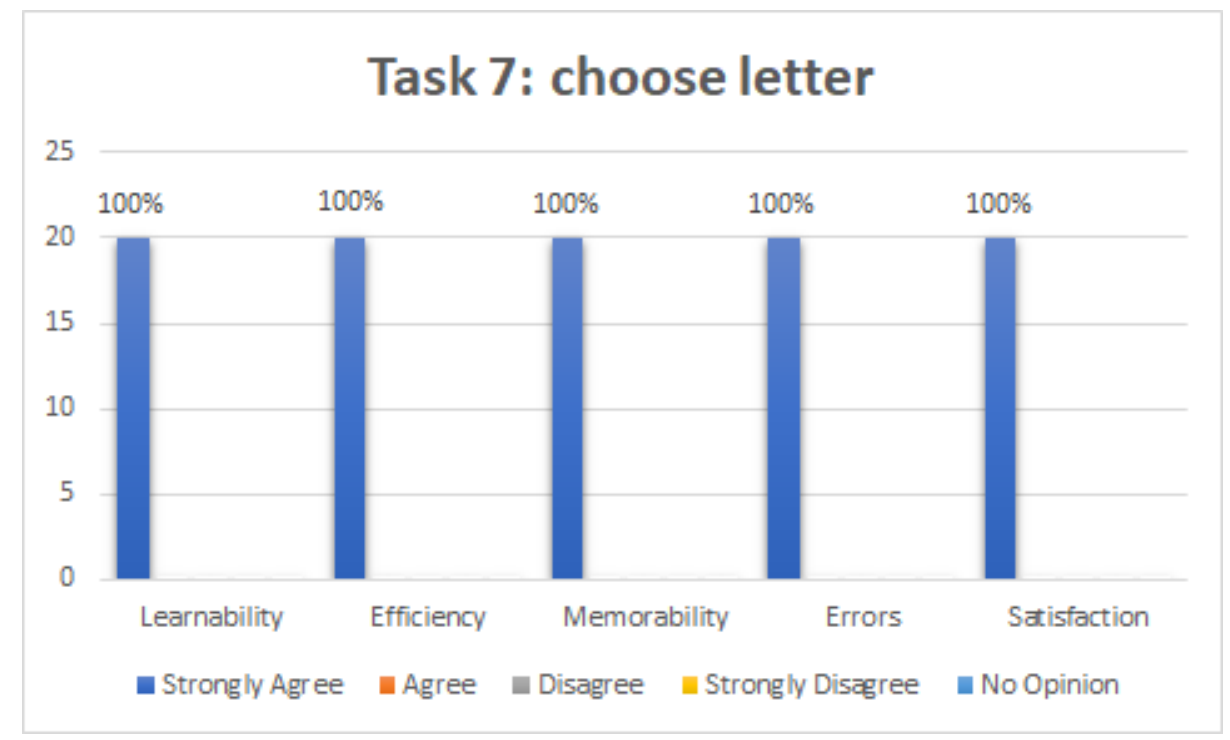

Fig. 9. pre-test "Task7" for children

Task 8: play tutorial

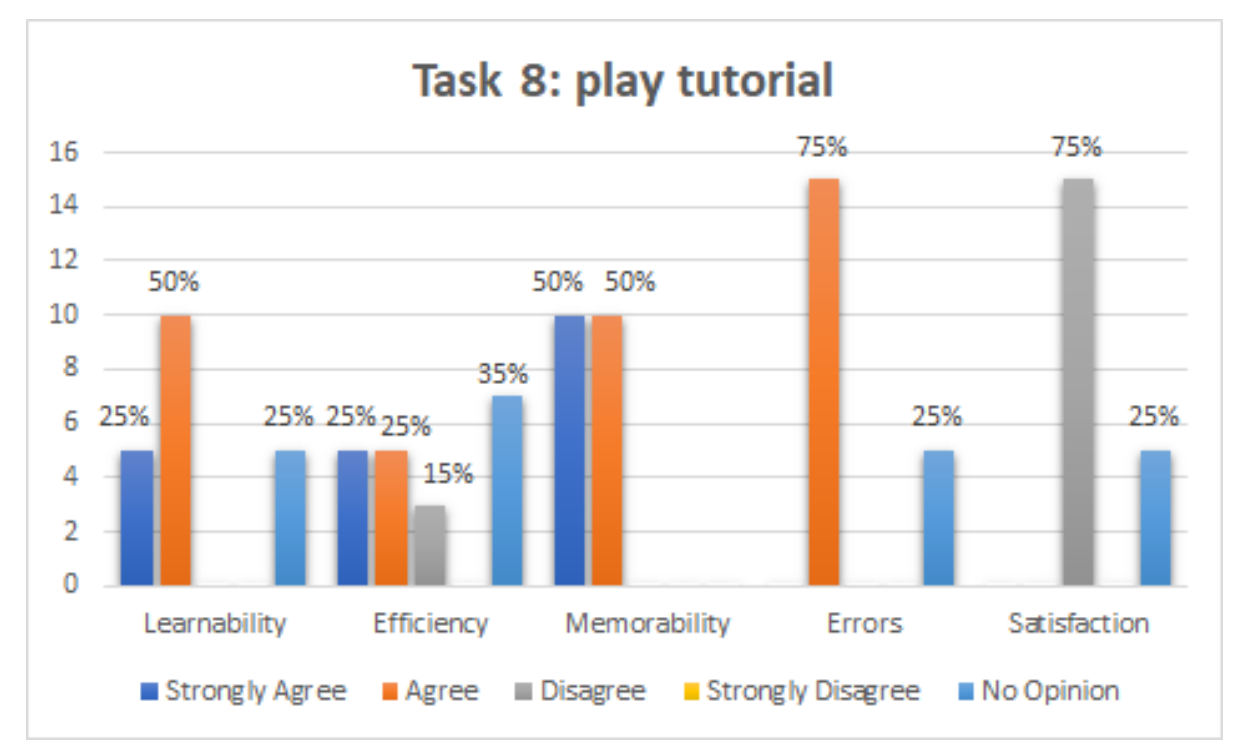

Fig. 10.pre-test "Task 8 " for children 
Task 9: view the result

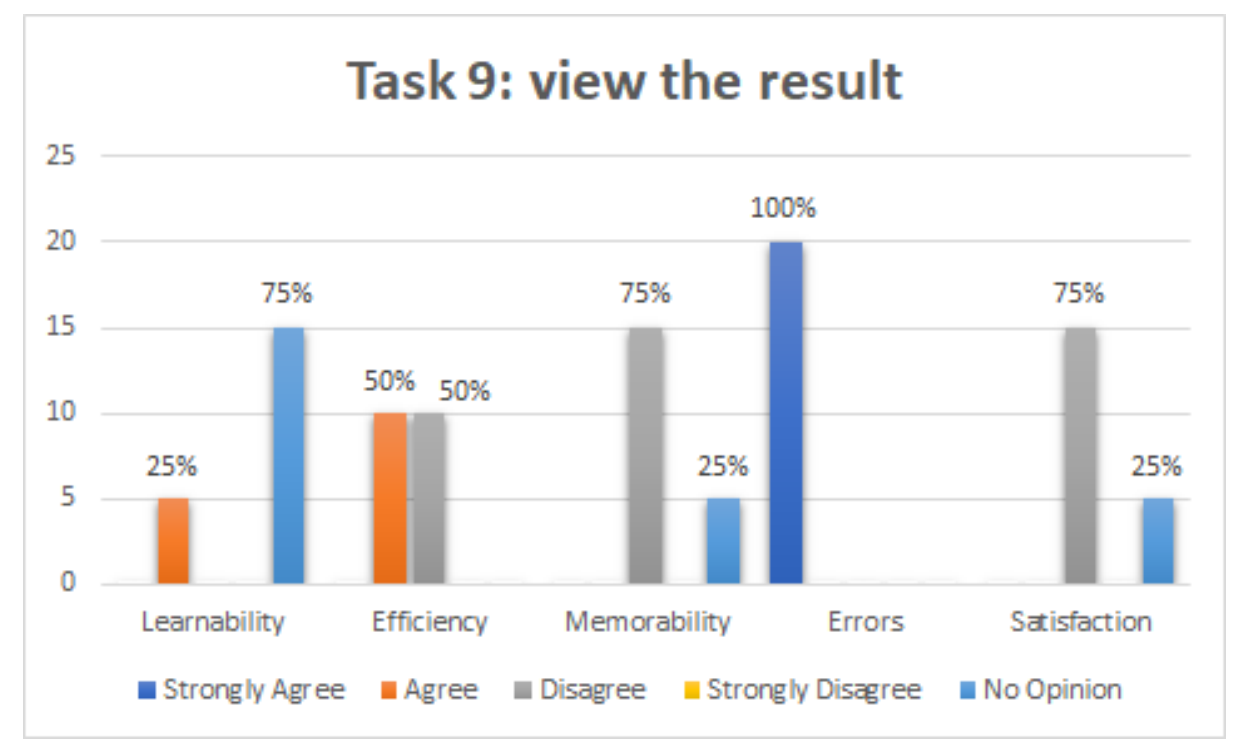

Fig. 11.pre-test "Task9" for children

\subsection{Problems and Recommendations of pretest:}

Problems and Recommendations are illustrated in tables 4 through 5:

Table 4. Problem 1

\section{Problem \# 1 (Task 8)}

Repetition Rate

Description

Suggestion and Recommendation
3 of the 20 children

They prefer to change the way the game tutorial display and start to make it clearer for them.

They suggest adding a video mark in the home screen when they click on it the tutorial start

Table 5. Problem 2

\section{Problem \# 2 (Task 9)}

Repetition Rate

Description

Suggestion and Recommendation
2 of the 20 children

They prefer to change the way the game result display

They suggest modifying the way that the game result displayed and to add more description to each result 


\subsection{Analyze the results of post-test questionnaire}

To know the opinion of the users about the application after writing all their feedbacks and suggestions. In the post-test questionnaire, we focus on the task that the users have problems with it in the previous time (Task8 and task 9 for the children).

\section{For children}

Task 8: play tutorial

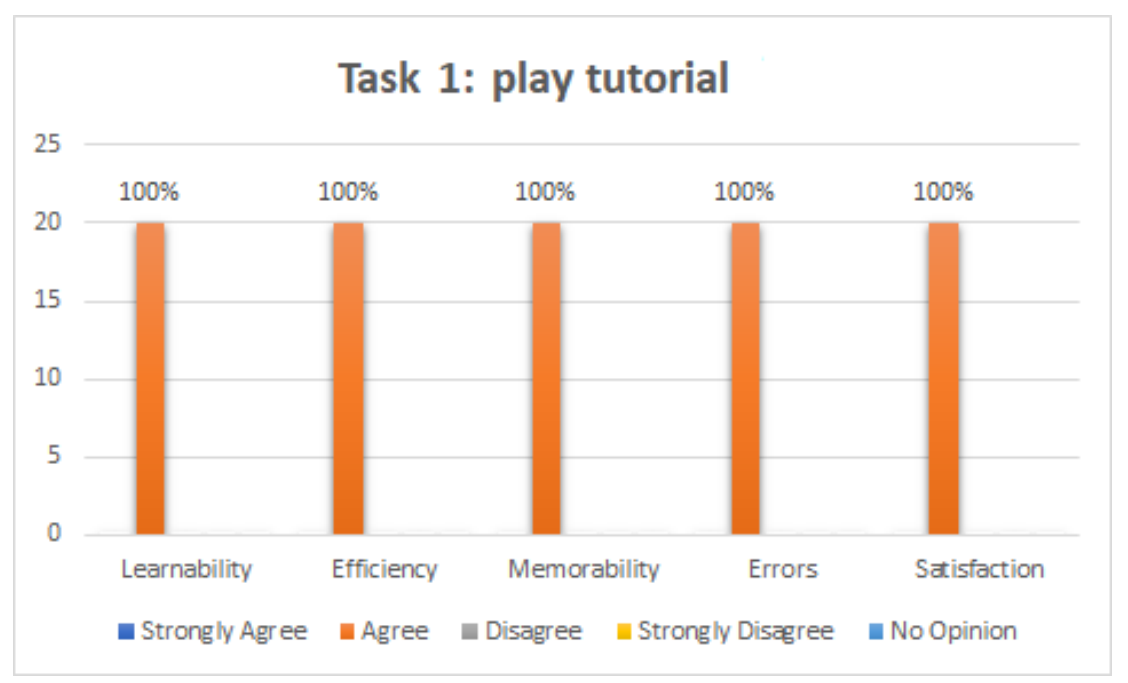

Fig. 12.post-test "Task1" for children

Task 9: view the result

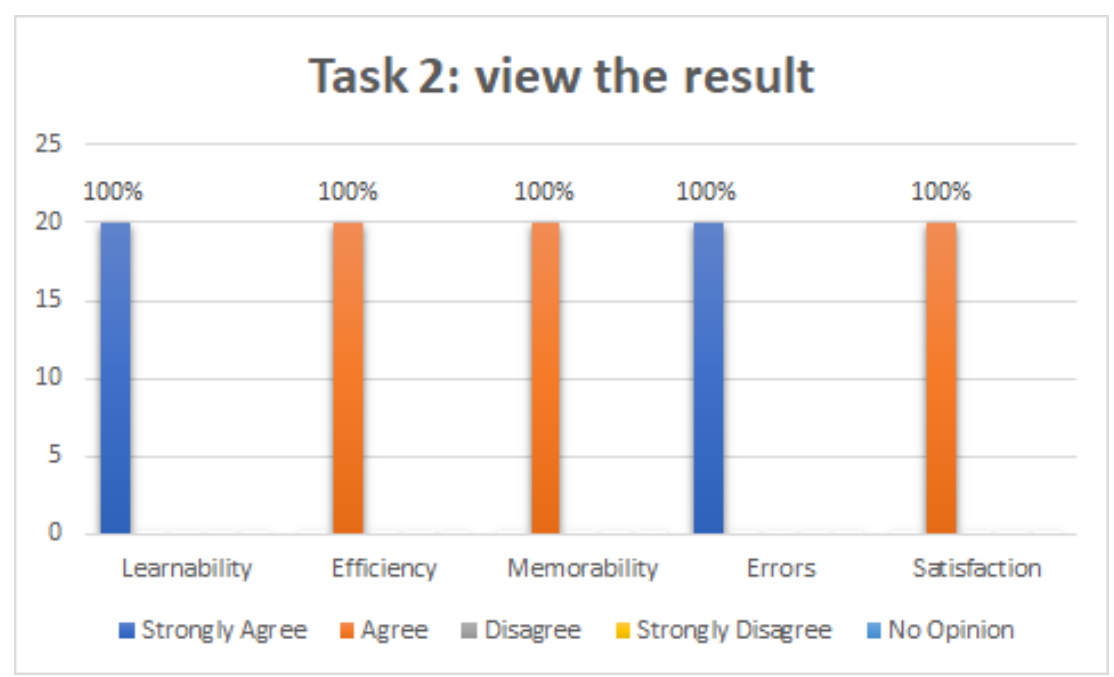

Fig. 13.post-test "Task2" for children 


\section{Conclusion}

The problems facing dyslexics, who suffer from a branch of learning disability that effects their literacy and understanding of new things, continue to increase. The improvement of these humans' wellbeing is not being specifically focused on by many researchers, although they also have the right to at least obtain primary education. Nevertheless, there are schools and various learning centres for dyslexic children and adults, although both are costly, or lack the proper structure through which they can provide the necessary education. This application's primary scope is the creation of a puzzle game application, based on eye tracking and a chatbot, for individuals posed with problems due to dyslexia, which is a neurobiological, specific learning disability. The ability to decipher words, spell correctly, or smoothly and precisely identify words, are all diminished by dyslexia. This application should be beneficial to individuals with dyslexia, parents of dyslexics, or experts such as reading professionals, educators and instructors who help dyslexics.

\section{References}

[1] 1000 Sight Words Superhero, Hetal Shah (2012), [Online] Available https://itunes.apple.com/us/app/1000-sight-words-superhero/id449497768?mt=8 [updated on Jan 10, 2012]

[2] 4 Pics 1 Word - Free , Lotum Gmbh(2017) , [Online] Available https://itunes.apple.com/ us/app/4-pics-1-word/id595558452?mt=8 [updated on Dec 13, 2017]

[3] A+ Spelling Test, Innovative Mobile Apps (2017), [Online] Available https://itunes.apple.com/us/app/a-spelling-test/id501211008? $\mathrm{mt}=8$ [updated on Mar 17, 2017]

[4] A1 Spelling App, Power Math Apps LLC (2010), [Online] Available https://itunes.apple.com/us/app/a1-spelling-app-free/id438784501? $\mathrm{mt}=8$ [updated on Oct $30,2017]$

[5] Abbasi, S., \&Kazi, H. (2014). Measuring effectiveness of learning chatbot systems on Student's learning outcome and memory retention. Asian Journal of Applied Science and Engineering, 3(2), 251-260.

[6] ABC Magic Phonics, Preschool University (2010), [Online] Available https://itunes.apple.com/us/app/abc-magic-phonics/id404048724?mt $=8$ [updated on Jun 26, 2017]

[7] Altanis, G., Boloudakis, M., Retalis, S., \&Nikou, N. (2013). Children with motor impairments play a kinect learning game: first findings from a pilot case in an authentic classroom environment. J Interact Design Architect, 19, 91-104.

[8] Campigotto, R., McEwen, R., \&Epp, C. D. (2013). Especially social: Exploring the use of an iOS application in special needs classrooms. Computers \& Education, 60(1), 74-86. https://doi.org/10.1016/j.compedu.2012.08.002

[9] Ganz, J. B., Earles-Vollrath, T. L., \& Cook, K. E. (2011). A visually based intervention for children with autism spectrum disorder. Teaching Exceptional Children, 43(6), 8-19. https://doi.org/10.1177/004005991104300601

[10] Goda, Y., Yamada, M., Matsukawa, H., Hata, K., \&Yasunami, S. (2014). Conversation with a Chatbot before an Online EFL Group Discussion and the Effects on Critical Think- 
Paper-Arabic Alphabetic Puzzle Game Using Eye Tracking and Chatbot for Dyslexia

ing. The Journal of Information and Systems in Education, 13(1), 1-7. https://doi.org/10.12937/ejsise.13.1

[11] Griffith University Annual Report, (2002), [Online] Available https://www.griffith.edu.au/ data/assets/pdf file/0003/138648/2002-annual-report.pdf

[12] Leo - Recorder \& Transcription , Zelig, LLC (2017), [Online] Available https:/itunes.apple.com/dk/app/leo-recorder-transcription/id1140324040?mt=8 [updated on 16 October 2017]

[13] Nielsen, J. (2003). Usability 101: Introduction to usability. Jakob Nielsen's Alertbox.

[14] Odhiambo, B. A., Okeyo, G., \&Cheruiyot, W. (2017). Framework for Improving Usability of Learning Management Systems by Integrating Pedagogical Agent. International Journal of Computer Applications, 166(8).

[15] Reading Machine - Full Install, Diana Sharp Consulting (2010), [Online] Available https://itunes.apple.com/us/app/reading-machine-full-install/id368974482? $\mathrm{mt}=8$ [updated on Sep 29, 2017]

[16] Rouse, techtarget. Retrieved from techtarget, [Online] Available at http://searchcrm.techtarget.com/definition/chatbot [Assessed on 26th March 2018]

[17] Satu, M. S., \&Parvez, M. H. (2015, November). Review of integrated applications with the AIML based chatbot. In Computer and Information Engineering (ICCIE), 2015 1st International Conference on (pp. 87-90). IEEE.

[18] Supporting Children with Dyslexia Strategies for Parents/Careers, East Sussex (2017), [Online] Available http://www.st-james-coldwaltham.w-sussex.sch.uk/docs/How to help your child with dyslexia $28129 . p d f$. [updated on 06 November 2017]

[19] The Dyslexia Toolkit, The National Center for Learning Disabilities (2012), [Online] Available http://www.readingrockets.org/sites/default/files/DyslexiaToolkit.pdf [updated on 2017]

[20] tobii, This is Eye Tracking. Retrieved from tobii, [Online] Available at https://www.tobii.com/group/about/this-is-eye-tracking/ [Assessed on 26th March 2018]

\section{Authors}

Nahla Aljojo is with the Faculty of Computing and Information Technology, Information Systems Department, University of Jeddah, Jeddah, Saudi Arabia (e-mail: naljojo@uj.edu.sa)

Asmaa Munshi is with the Faculty of Computing and Information Technology, Information Systems Department, University of Jeddah, Jeddah, Saudi Arabia (e-mail: amamunshi@uj.edu.sa)

Wfaa Almukadi is with the Faculty of Computing and Information Technology, Information Systems Department, University of Jeddah, Jeddah, Saudi Arabia (email: walmukadi@uj.edu.sa)

Anhar Hossain is with the Faculty of Computing and Information Technology, Information Systems Department, King Abdulaziz University, Jeddah, Saudi Arabia. (email: anharhossain11@gmail.com)

Noran Omar is with the Faculty of Computing and Information Technology, Information Systems Department, King Abdulaziz University, Jeddah, Saudi Arabia.

Bashair Aqel is with the Faculty of Computing and Information Technology, Information Systems Department, King Abdulaziz University, Jeddah, Saudi Arabia. 
Shahad Almhuemli is with the Faculty of Computing and Information Technology, Information Systems Department, King Abdulaziz University, Jeddah, Saudi Arabia.

Fatma Asirri is with the Faculty of Computing and Information Technology, Information Systems Department, King Abdulaziz University, Jeddah, Saudi Arabia.

Areej Alshamasi is with the Faculty of Economics and Administration, Public Administration Department, King Abdulaziz University, Jeddah, Saudi Arabia. (email: aalshamasi@kau.edu.sa)

Article submitted 02 June 2018. Resubmitted 20 July and 10 August 2018. Final acceptance 13 August 2018. Final version published as submitted by the authors. 